\title{
Investigating the Factors of Committing Crimes using Fuzzy Topsis
}

\author{
Norwaziah Mahmud ${ }^{1 *}$, Siti Hafawati Jamaluddin², Nur Azarina Omar ${ }^{3}$ Nur Syuhada \\ Muhammat Pazil ${ }^{4}$ \\ ${ }^{1}$ Faculty of Computer \& Mathematical Sciences, Universiti Teknologi MARA Perlis Branch, Malaysia \\ ${ }^{4}$ Faculty of Computer \& Mathematical Sciences, Universiti Teknologi MARA Melaka Branch, Malaysia \\ Corresponding author: *norwaziah@perlis.uitm.edu.my \\ Received Date: 7 August 2018 \\ Accepted Date: 4 October 2018
}

\begin{abstract}
It is a major concern for everyone when crime activities are on the rise particularly, if the crimes are happening near them. There is still lack of findings and understanding on the reasons for the occurrence of crimes albeit all the hue and cry. This study is to investigate the significant factors of committing crimes and also their respective ranking. The method of Fuzzy Technique for Order Preference by Similarity to Ideal Solution (TOPSIS) was applied in this study. Fuzzy TOPSIS is commonly used for ranking purpose and selecting multi-criteria variables. Hence, this method is remarkably successful in determining the ranking of the factors as it relates to different criteria and alternatives. In this study, three decision makers are required to evaluate the factors using linguistic variables which vary from 'very poor' to 'very good'. After applying fuzzy TOPSIS, the factors are ranked, thus the results show that lack of education is the major factor that contributes to crime behaviour with closeness coefficient value of 0.4661. The least contributing factor with closeness coefficient value of 0.3632 comes from poverty. The results of this study may be worthwhile for many personnel. Future research may expand the work with different types of criteria and alternatives.
\end{abstract}

Keywords: fuzzy TOPSIS, crimes, ranking, multi-attribute decision making

\section{INTRODUCTION}

Nowadays, there are numerous heart breaking and awful news that are related to crime. It has become a major issue in Malaysia. As the country continues to be modernized, the crime rate is supposed to be descended. However, the opposite happens in most countries, including Malaysia. According to Khan (2015), the measurers of crime can be categorized into two. First, is the official crime statistics, which is based on the total records of the offenders and also the offences that are processed by the police, courts and also prison agencies. Second, is the unofficial crime statistics which comes from the surveys outside the criminal justice system. Many Malaysians are becoming more concerned about this issue. The issue of crimes in Malaysia can be seen in a study by Sidhu (2005) as he claimed that even though there is an improvement in the Malaysian Quality of Life Index (MQLI) during the period of 1990 to 2002 by 9.8 points, public safety and environment show a downward trend thus showing a rise in the index crime statistics. This issue should catch the eye of every person in the country so that they can be more alert about crime issue that is happening around them. Malaysian Digest (2014) stated that in 2013 itself, juvenile crime shows an increment and based on a statistics from the Royal Malaysian Police in Bukit Aman, 7,816 juvenile cases were recorded and mostly involved school students.

The crime rate in Malaysia has increased over the time. According to Shahrudin (2016), there is an increase of 4.6\% recorded in the crime index between January and April in 2016 because of the increment in property crimes. The issue of crimes have been making the headlines for the past few years. On top of 
that, there are limited studies on finding the causes of committing crime. In order to decrease the problem, the government can join the police department in analysing the factors that contribute the most in committing crime in Malaysia. Hence, the actions that can be executed so that crime behaviour in Malaysia can be reduced can be pointed out. The behaviour of committing crimes in Malaysia can be due to many factors. The factors involved are peer pressure, poverty, lack of education, family condition or background and lastly alcohol and drug abuse (The Times of India (2016); Ghani (2017); The Hindu (2016); Esiri (2016); Lochner (2004); Anspal et al. (2011); Brown and Velasquez (2017)). The factors listed will act as the alternatives of the study. In order to decide the ranking of factors that cause crimes to be committed, this research was proposed.

\section{FACTORS OF COMMITTING CRIME}

\section{Poverty}

Poverty is associated with insufficient income or shortage of first necessity goods. Crime rates appear to be notably high in deprive neighbourhoods where mostly the residents are in the state of poverty. Justice Markandey Katju who is a former Supreme Court judge in India stated to The Times of India (2016) that poverty is the main reason of committing crime and most of the people found in jails in India, in America and other countries are poor. According to Ghani (2017), there are quite a number of scholars of criminology which claimed that poverty often tied to be the main cause of committing crime in many societies. The societies that suffer from poverty are troubled with financial difficulties, high cost of living and ultimately hard to get a complete meal for a day. As a consequence, the tendency to commit crime by the societies may be higher.

\section{Family Conditions}

Crime behaviour might be influenced by family. A survey has been conducted in India, where the interview was done in detention centres across Delhi, Odisha, Tamil Nadu and Kerala. A total of 605 children has participated in the survey. The survey showed that a majority of the children is came from families which showed exposure in various natures. The results obtained showed that frequent feud and squabble between parents or even children and parents contributed $50 \%$ of the results. Moreover, family disruptions such as single-parent families, divorced parents and living in streets contributed $41.5 \%$ (The Hindu, 2016).

\section{Peer pressure}

As reported by Esiri (2016), growing children look up to their peer group as their idol which makes it an upsetting and alarming social problem. As children grow into teenagers, the problems become bigger if parental bonding is weak. A conclusion made from the study is that peer pressure and its effect do occur in all adolescents. It also acts as a prime source of juvenile delinquency and adulthood crime, which obviously a concern to the society. Esiri also stated that teenagers normally have the desire to attach to their peers when there are problems at home. To relate, a teenager is most likely to be drawn to a group which is involved in immoral activities such as theft, cultism and etc.

\section{Lack of Education}

Education plays an important role in life. Crime can be attributed to the lack of education on the part of the perpetrator or their families. As reported by The Times of India (2016), in 2015, a total of 7870 juveniles were apprehended. Out of this number, there are only 3261 juveniles who had educational background until higher secondary. 3088 of them studied until primary level and 902 were illiterate. This 
record was according to the National Records Crime Bureau (NRCB) data. Furthermore, according to Lochner (2004), among young uneducated men, violent and property crimes are the main problem. In his study, Lochner implied that it is because of their low skill levels, which imply incarceration costs for committing crime. On top of that, a study done by Anspal et al. (2011) recorded that the probabilities of crime execution are higher among people who have lower levels of education, younger people and also males. The impact of education is noticeable for younger people and it will slowly fade once they are around their sixties.

\section{Alcohol and Drug Abuse}

According to Brown and Velasquez (2017) on drug-related crime in Mexico, a statistics reported by the National Institute of Statistics and Geography (INEGI), a stable and declining homicide rates were shown from mid 1990s until 2007. However, the homicide rate per 100,000 people increased rapidly by nearly 200\% between 2007 and 2010. When examined specifically, most of the increment in the homicide rate found in the statistics is due to the surge in drug-related violence crime in Mexico.

\section{TECHNIQUE FOR ORDER PREFERENCE BY SIMILARITY TO IDEAL SOLUTION (TOPSIS)}

Technique for Order Preference by Similarity to Ideal Solution (TOPSIS) was first proposed by Hwang and Yoon back in 1981 and is one of the Multi-Attribute Decision Making (MADM) techniques. When a user prefers a simpler weighting approach, TOPSIS is the right technique (Kabir \& Hasin, 2012). There are two artificial alternatives which are Positive-Ideal Solution (PIS) and Negative-Ideal Solution (NIS). PIS will maximize the benefit criteria and minimize the cost criteria making it the best for all attributes. In contrast, NIS will maximize the cost criteria and minimize the benefit criteria. NIS is the one which has the worst attributes value (Erdebilli \& Saputro, 2013).

A few years back, some fuzzy TOPSIS methods were developed in different applied field. Azizi et al. (2015) conducted a study to rank automotive suppliers using this method. The main criteria identified from the study were responsibility, flexibility, competency and speed. 18 sub-criteria were considered based on four factories which were factory A, B, C and D. Result shows that the best supplier is from factory A and the worst is factory D. It can be concluded that based on the Fuzzy TOPSIS result, there are many strategies that can be implemented by the suppliers so that the bottlenecks can be found if it exists and responds to the supply chain if there are any rapid changes. In addition, Abdullah and Zamni (2010) compared between fuzzy TOPSIS and correlation analysis to rank the factors associated with road accidents. Based on their studies, fuzzy TOPSIS is the best alternative and the most suitable technique for solving a group decision-making problem under fuzzy environment.

Mor and Ramachandran (2017) conducted a study to select the best strategy to optimize solid wastes disposal. The method used was Fuzzy TOPSIS. There are five strategies that were listed which are landfills, incineration, energy transform, reuse and recycle. After analysing the result, the best strategy that can be used is recycle as its closeness coefficient value is 0.5561 which is the greatest out of all strategies hence making it the highest ranking. This proves that Fuzzy TOPSIS is able in aiding the selection of the best option to achieve the best result.

\section{METHODOLOGY}

The data on crime factors are collected by interviewing and providing questionnaires to the personnel in Seri Manjung District Police Headquarters (IPD), Perak. There are three personnel who were chosen to be 
the decision makers. All the three of them were asked to rate the criteria with respect to the alternatives. The rating varies from 'very low' (VL), 'low' (L), 'medium' (M), 'high' (H) and 'very high' (VH).

\section{Fuzzy Theory Concepts}

A fuzzy set $\tilde{a}$ in a universe of discourse $X$ is characterized by a membership function $\mu_{\tilde{a}}(x)$ that maps each element $x$ in $X$ to a real number in the interval $[0,1]$. The function value $\mu_{\tilde{a}}(x)$ is termed the grade of membership of $x$ in $\tilde{a}$. The grade of membership will be higher if the value of $\mu_{\tilde{a}}(x)$ is near to unity.

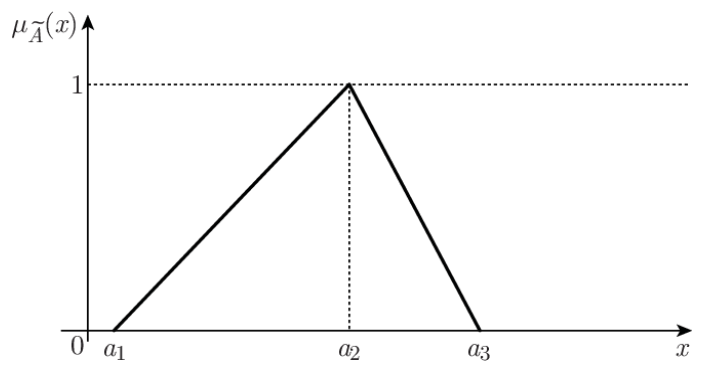

Figure 1: A triangular fuzzy number for membership function, $\mu_{\tilde{a}}(x)$.

Representation of triplet $\tilde{a}=\left(a_{1}, a_{2}, a_{3}\right)$ is used for a triangular fuzzy number. The membership function, $\mu_{\tilde{a}}(x)$ of a triangular fuzzy number $\tilde{a}$ is given as:

$\mu_{\tilde{a}}(x)=\left\{\begin{array}{cc}\frac{x-a_{1}}{a_{2}-a_{1}}, & \text { if } a_{1} \leq x \leq a_{2} \\ \frac{a_{3}-x}{a_{3}-a_{2}}, & \text { if } a_{2} \leq x \leq a_{3} \\ 0 & \text { otherwise }\end{array}\right.$

where $a_{1}, a_{2}, a_{3}$ are real numbers. The maximal grade of $\mu_{\tilde{a}}(x)$ is 1 which is given by $a_{2}$ while the minimal grade of $\mu_{\tilde{a}}(x)$ which is 0 is given by $a_{1} a_{1}$ and ${ }^{a_{3}}$ are the lower and upper bounds of the available area for evaluation data. Let $\tilde{a}=\left(a_{1}, a_{2}, a_{3}\right)$ and $\tilde{b}=\left(b_{1}, b_{2}, b_{3}\right)$ be two triangular fuzzy numbers. The distance between the numbers can be calculated by using vertex method:

$d(\tilde{a}, \tilde{b})=\sqrt{\frac{1}{3}\left[\left(a_{1}-b_{1}\right)^{2}+\left(a_{2}-b_{2}\right)^{2}+\left(a_{3}-b_{3}\right)^{2}\right]}$

\section{Linguistic Variable}

There are some conversion scales that were applied in order to transform linguistic terms into fuzzy number. Referring to Sodhi and Prabhakar (2012), a scale of 1 to 9 is used to rate the criteria and the alternatives. The fuzzy ratings for linguistic variable can be summarized as below: 
Table 1: Fuzzy Ratings for Linguistic Variables

\begin{tabular}{lll}
\hline Fuzzy Number & Alternative Assessment & \multicolumn{1}{c}{ QA Weights } \\
\hline$(1,1,3)$ & Very Poor (VP) & Very Low (VL) \\
$(1,3,5)$ & Poor (P) & Low (L) \\
$(3,5,7)$ & Fair (F) & Medium (M) \\
$(5,7,9)$ & Good (G) & High (H) \\
$(7,9,9)$ & Very Good (VG) & Very High (VH) \\
& & \\
\hline
\end{tabular}

(Source: Sodhi \& Prabhakar, 2012)

\section{FUZZY TOPSIS IN DETERMINING THE FACTORS OF COMMITTING CRIMES}

There are five alternatives and five criteria used in this study. The alternatives are peer pressure, poverty, lack of education, family condition and also drug and alcohol abuse. Meanwhile the criteria are the immigrant, youth, unemployed, ex-criminal and desperate individual. The alternatives and criteria will be used to determine the significant factors of committing crimes. Figure 2 shows all the criteria and alternatives in determining the factors of committing crime.

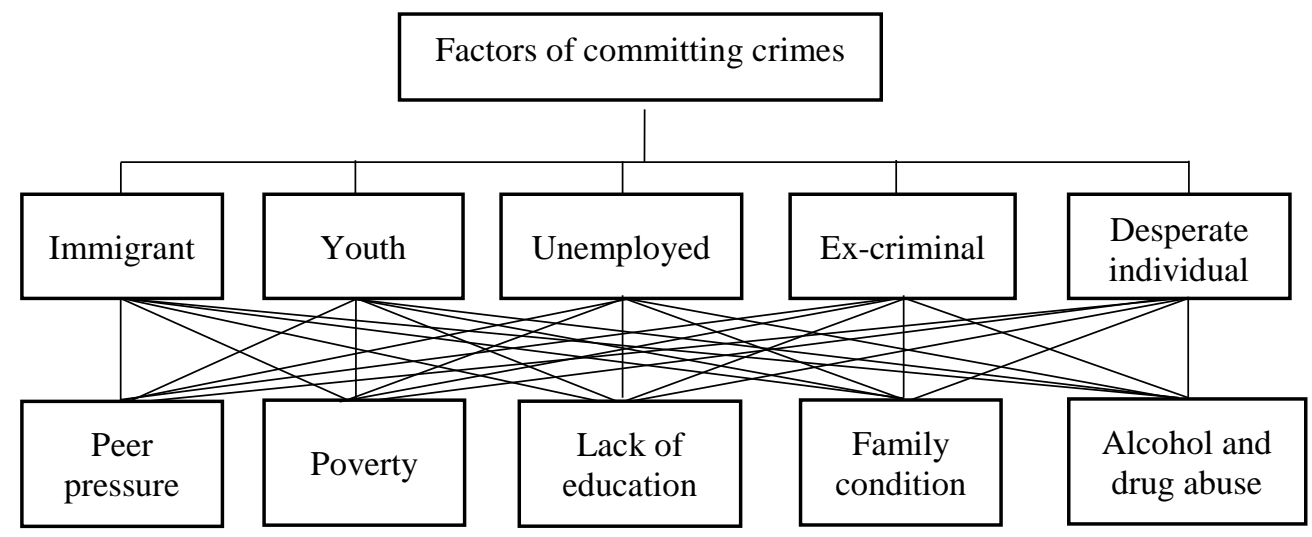

Figure 2: Criteria and alternative in determining the factors of committing crimes.

\section{STEPS IN FUZZY TOPSIS}

To summarize, the steps of Fuzzy TOPSIS are as follows:

Step 1: To obtain the fuzzy weight $\tilde{b}_{x y}$ of criterion $C_{y}$, the weight of criteria must be aggregated by using equation (2). Pool the decision makers' ratings by using equation (3) to obtain the aggregated fuzzy rating $\tilde{a}_{x y}^{j}$ of alternative $A_{x}$.

$$
\begin{aligned}
& b_{y 1}=\min _{j}\left\{b_{y j 1}\right\}, \quad b_{y 1}=\frac{1}{J} \sum_{j=1}^{J} b_{y j 2}, \quad b_{y 1}=\max _{j}\left\{b_{y j 3}\right\} \\
& p_{x y}=\min _{j}\left\{p_{x y}^{j}\right\}, \quad q_{x y}=\frac{1}{J} \sum_{j=1}^{J} q_{x y}^{j}, \quad r_{x y}=\max _{j}\left\{r_{x y}^{j}\right\}
\end{aligned}
$$

Step 2: Construct the fuzzy decision matrix and the normalized fuzzy decision matrix by using equations (4), (5), and (6) 


$$
\tilde{Z}=\left[\tilde{z}_{x y}\right]_{m \times n}, \quad x=1,2, \ldots, m ; y=1,2 \ldots, n
$$

where:

$$
\begin{aligned}
& \tilde{z}_{x y}=\left(\frac{p_{x y}}{r_{y}^{*}}, \frac{q_{x y}}{r_{y}^{*}}, \frac{r_{x y}}{r_{y}^{*}}\right) \text { and } r_{y}^{*}=\max _{x} r_{x y} \text { (benefit criteria) } \\
& \tilde{z}_{x y}=\left(\frac{p_{y}^{-}}{r_{x y}}, \frac{p_{y}^{-}}{q_{x y}}, \frac{p_{y}^{-}}{p_{x y}}\right) \text { and } p_{y}^{-}=\min _{x} p_{x y}(\cos t \text { criteria })
\end{aligned}
$$

Step 3: Construct the weighted normalized fuzzy decision matrix by using equation (7).

$$
\begin{gathered}
\widetilde{G}=\left[\tilde{g}_{x y}\right]_{m \times n}, \quad x=1,2, \ldots, m ; y=1,2 \ldots, n \\
\text { where } \tilde{g}_{x y}=\tilde{z}_{x y} \times \tilde{b}_{y}
\end{gathered}
$$

Step 4: Determine FPIS and FNIS. For each alternative from FPIS and FNIS, calculate the distance by using equations (8), (9), (10) and (11) respectively.

$$
\begin{aligned}
& P^{*}=\tilde{g}_{1}^{*}, \tilde{g}_{2}^{*}, \ldots \tilde{g}_{n}^{*} \text { where } \tilde{g}_{y}^{*}=(1,1,1) \\
& P^{-}=\tilde{g}_{1}^{-}, \tilde{g}_{2}^{-}, \ldots \tilde{g}_{n}^{-} \text {where } \tilde{g}_{y}^{-}=(0,0,0)
\end{aligned}
$$

The distance of each weighted alternative, $d_{x}^{*}$ and $d_{x}^{-}$can be computed as follows:

$$
\begin{aligned}
& d_{x}^{*}=\sum_{\mathrm{y}=1}^{\mathrm{n}} d_{g}\left(\tilde{g}_{x y}, \tilde{g}_{y}^{*}\right), \quad x=1,2, \ldots, m \\
& d_{x}^{-}=\sum_{\mathrm{y}=1}^{\mathrm{n}} d_{g}\left(\tilde{g}_{x y}, \tilde{g}_{y}^{-}\right), \quad x=1,2, \ldots, m
\end{aligned}
$$

Step 5: Calculate the closeness coefficient of each alternative and then rank the alternatives using equation (12).

$$
C C_{x}=\frac{d_{x}^{-}}{d_{x}^{-}+d_{x}^{*}}, \quad x=1,2, \ldots, m
$$

\section{RESULTS AND DISCUSSION}

The method of Fuzzy TOPSIS was used in this study to determine and rank the factors of committing crime. Three personnel of IPD Seri Manjung, Perak were chosen to be the decision makers, referring as DM1, DM2 and DM3. All of the decision makers were involved in the interview conducted and they were required to rate the five alternatives which are poverty (A1), family conditions (A2), peer pressure (A3), lack of education (A4) and lastly, alcohol and drug abuse (A4) with respect to the five criteria which are youth (C1), unemployed (C2), ex-criminal (C3), desperate individual (C4) and immigrant (C5) on the given questionnaire. The decision makers used the linguistic variables as shown in Table 1 to evaluate the rating of the alternatives with respect to each criterion. The results of the interview were collected and pooled together. The important weight of the criteria assessed by the decision makers was presented in Table 2. In addition, Table 3 depicts the evaluation of the alternatives with respect to each of the criteria. 
Table 2: The Important Weight of the Criteria.

\begin{tabular}{llll}
\hline \multirow{2}{*}{ Criteria } & \multicolumn{3}{l}{ Decision Maker } \\
\cline { 2 - 4 } & DM1 & DM2 & DM3 \\
\hline C1 & $\mathrm{M}$ & $\mathrm{H}$ & $\mathrm{M}$ \\
C2 & $\mathrm{H}$ & $\mathrm{VH}$ & $\mathrm{H}$ \\
C3 & $\mathrm{M}$ & $\mathrm{H}$ & $\mathrm{L}$ \\
C4 & $\mathrm{H}$ & $\mathrm{H}$ & $\mathrm{H}$ \\
C5 & $\mathrm{M}$ & $\mathrm{M}$ & $\mathrm{M}$ \\
\hline
\end{tabular}

Table 3: The Ratings of the Alternatives.

\begin{tabular}{|c|c|c|c|c|}
\hline \multirow{2}{*}{ Criteria } & \multirow{2}{*}{ Alternative } & \multicolumn{3}{|c|}{ Decision Maker } \\
\hline & & DM1 & DM2 & DM3 \\
\hline \multirow[t]{5}{*}{$\overline{C 1}$} & $\mathrm{~A} 1$ & $\mathrm{G}$ & $\mathrm{F}$ & $\bar{F}$ \\
\hline & $\mathrm{A} 2$ & VG & VG & G \\
\hline & A3 & $\mathrm{G}$ & $\mathrm{G}$ & $P$ \\
\hline & A4 & $G$ & $G$ & VG \\
\hline & A5 & $\mathrm{F}$ & $\mathrm{F}$ & $P$ \\
\hline \multirow[t]{5}{*}{ C2 } & $\mathrm{A} 1$ & VG & $G$ & $\mathrm{G}$ \\
\hline & $\mathrm{A} 2$ & $\mathrm{G}$ & $G$ & $\mathrm{G}$ \\
\hline & A3 & $G$ & $\mathrm{~F}$ & $\mathrm{~F}$ \\
\hline & A4 & $\mathrm{G}$ & $\mathrm{F}$ & $P$ \\
\hline & A5 & $P$ & $P$ & $P$ \\
\hline \multirow[t]{5}{*}{ C3 } & $\mathrm{A} 1$ & VG & $\mathrm{G}$ & VG \\
\hline & $\mathrm{A} 2$ & $\mathrm{~F}$ & $P$ & $\mathrm{G}$ \\
\hline & A3 & $\mathrm{F}$ & $\mathrm{F}$ & $\mathrm{F}$ \\
\hline & A4 & $G$ & $\mathrm{~F}$ & G \\
\hline & A5 & $\mathrm{F}$ & $\mathrm{F}$ & $\mathrm{P}$ \\
\hline \multirow[t]{5}{*}{ C4 } & $\mathrm{A} 1$ & $\mathrm{G}$ & $\mathrm{G}$ & $G$ \\
\hline & $\mathrm{A} 2$ & $G$ & $\mathrm{~F}$ & $\mathrm{~F}$ \\
\hline & A3 & $G$ & $P$ & $\mathrm{P}$ \\
\hline & A4 & $\mathrm{F}$ & $\mathrm{F}$ & $P$ \\
\hline & A5 & $\mathrm{P}$ & $\mathrm{P}$ & $\mathrm{P}$ \\
\hline \multirow[t]{5}{*}{ C5 } & $\mathrm{A} 1$ & $\mathrm{~F}$ & $\mathrm{~F}$ & $\mathrm{P}$ \\
\hline & $\mathrm{A} 2$ & $G$ & $G$ & $\mathrm{G}$ \\
\hline & A3 & $G$ & $G$ & $G$ \\
\hline & A4 & $G$ & $G$ & $\mathrm{~F}$ \\
\hline & A5 & $\mathrm{P}$ & $\mathrm{P}$ & $\mathrm{P}$ \\
\hline
\end{tabular}

The aggregated fuzzy weight $\tilde{b}_{x y}$ of the criterion (see Table 4) is computed by equation (2). 
Table 4: The Aggregated Fuzzy Weight of Each Criteria.

\begin{tabular}{ll}
\hline Criteria & Aggregated Fuzzy Weight \\
\hline C1 & $(3.000,5.667,9.000)$ \\
C2 & $(5.000,7.667,9.000)$ \\
C3 & $(1.000,5.000,9.000)$ \\
C4 & $(5.000,7.000,9.000)$ \\
C5 & $(3.000,5.000,7.000)$ \\
\hline
\end{tabular}

Table 5: Aggregated Fuzzy Rating of Alternative.

\begin{tabular}{llllll}
\hline \multirow{2}{*}{ Criteria } & Alternative & \multicolumn{5}{l}{} \\
\cline { 2 - 6 } & $\mathrm{A} 1$ & $\mathrm{~A} 2$ & $\mathrm{~A} 3$ & $\mathrm{~A} 4$ & $\mathrm{~A} 5$ \\
\hline C1 & $(3,5.667,9)$ & $(5,7.667,9)$ & $(5,8.333,9)$ & $(5,7.000,9)$ & $(1,4.333,7)$ \\
C2 & $(5,8.333,9)$ & $(5,7.000,9)$ & $(1,5.000,9)$ & $(3,5.667,9)$ & $(5,7.000,9)$ \\
C3 & $(1,5.667,9)$ & $(3,5.667,9)$ & $(3,5.000,7)$ & $(1,4.333,9)$ & $(5,7.000,9)$ \\
C4 & $(5,7.667,9)$ & $(1,5.000,9)$ & $(3,6.333,9)$ & $(1,4.333,7)$ & $(3,6.333,9)$ \\
C5 & $(1,4.333,7)$ & $(1,3.000,5)$ & $(1,4.333,7)$ & $(1,3.000,5)$ & $(1,3.000,5)$ \\
\hline
\end{tabular}

Aggregated fuzzy rating of alternative is computed using equation (3). Table 6 shows the normalized fuzzy decision matrix for benefit criteria computed using equation (5). Benefit criteria is obtained from the maximum value in the aggregated fuzzy ratings of the alternatives.

Table 6: Normalized Fuzzy Decision Matrix (Benefit Criteria).

\begin{tabular}{|c|c|c|c|c|c|}
\hline \multirow{2}{*}{ Criteria } & \multicolumn{5}{|l|}{ Alternative } \\
\hline & A1 & $\mathrm{A} 2$ & A3 & A4 & A5 \\
\hline C1 & $(0.333,0.630,1)$ & $(0.556,0.852,1)$ & $(0.556,0.926,1)$ & $(0.556,0.778,1)$ & $(0.111,0.481,0.778)$ \\
\hline $\mathrm{C} 2$ & $(0.556,0.926,1)$ & $(0.556,0.778,1)$ & $(0.111,0.556,1)$ & $(0.333,0.630,1)$ & $(0.556,0.778,1)$ \\
\hline C3 & $(0.111,0.630,1)$ & $(0.333,0.630,1)$ & $(0.333,0.556,0.778)$ & $(0.111,0.481,1)$ & $(0.556,0.778,1)$ \\
\hline C4 & $(0.556,0.852,1)$ & $(0.111,0.556,1)$ & $(0.333,0.704,1)$ & $(0.111,0.481,0.778)$ & $(0.333,0.704,1)$ \\
\hline C5 & $(0.111,0.481,0.778)$ & $(0.111,0.333,0.556)$ & $(0.111,0.481,0.778)$ & $(0.111,0.333,0.556)$ & $(0.111,0.333,0.556)$ \\
\hline
\end{tabular}

Table 7 shows the normalized fuzzy decision matrix for cost criteria computed using equation (6). Cost criteria is obtained from the minimum value in the aggregated fuzzy ratings of the alternatives.

Table 7: Normalized Fuzzy Decision Matrix (Cost Criteria).

\begin{tabular}{|c|c|c|c|c|c|}
\hline \multirow{2}{*}{ Criteria } & \multicolumn{5}{|l|}{ Alternative } \\
\hline & $\mathrm{A} 1$ & $\mathrm{~A} 2$ & A3 & A4 & A5 \\
\hline C1 & $(0.111,0.176,0.333)$ & $(0.111,0.130,0.200)$ & $(0.111,0.120,0.200)$ & $(0.111,0.143,0.200)$ & $(0.143,0.231,1)$ \\
\hline C2 & $(0.111,0.120,0.200)$ & $(0.111,0.143,0.200)$ & $(0.111,0.200,1)$ & $(0.111,0.176,0.333)$ & $(0.111,0.143,0.200)$ \\
\hline C3 & $(0.111,0.176,1)$ & $(0.111,0.176,0.333)$ & $(0.143,0.200,0.333)$ & $(0.111,0.231,1)$ & $(0.111,0.143,0.200)$ \\
\hline C4 & $(0.111,0.130,0.200)$ & $(0.111,0.200,1)$ & $(0.111,0.158,0.333)$ & $(0.111,0.231,1)$ & $(0.111,0.158,0.333)$ \\
\hline C5 & $(0.143,0.231,1)$ & $(0.200,0.333,1)$ & $(0.143,0.231,1)$ & $(0.200,0.333,1)$ & $(0.200,0.333,1)$ \\
\hline
\end{tabular}


Table 8: Weighted Normalized Fuzzy Decision Matrix (Benefit Criteria).

\begin{tabular}{|c|c|c|c|c|c|}
\hline \multirow{2}{*}{ Criteria } & \multicolumn{5}{|l|}{ Alternative } \\
\hline & $\mathrm{A} 1$ & $\mathrm{~A} 2$ & $\mathrm{~A} 3$ & $\mathrm{~A} 4$ & A5 \\
\hline C1 & $(1,3.568,9)$ & $(1.667,4.827,9)$ & $(1.667,5.247,9)$ & $(1.667,4.407,9)$ & $(0.333,2.728,7)$ \\
\hline C2 & $(2.778,7.099,9)$ & $(2.778,5.963,9)$ & $(0.556,4.259,9)$ & $(1.667,4.827,9)$ & $(2.778,5.963,9)$ \\
\hline C3 & $(0.111,3.148,9)$ & $(0.333,3.148,9)$ & $(0.333,2.778,7)$ & $(0.111,2.407,9)$ & $(0.556,3.889,9)$ \\
\hline C4 & $(2.778,5.963,9)$ & $(0.556,3.889,9)$ & $(1.667,4.926,9)$ & $(0.556,3.370,7)$ & $(1.667,4.926,9)$ \\
\hline C5 & $(0.333,2.407,5.444)$ & $(0.333,1.667,3.889)$ & $(0.333,2.407,5.444)$ & $(0.333,1.667,3.889)$ & $(0.333,1.667,3.889)$ \\
\hline
\end{tabular}

Weighted normalized fuzzy decision matrix is tabulated in Table 8 and Table 9 respectively. Table 8 is for benefit criteria meanwhile Table 9 is for cost criteria.

Table 9: Weighted Normalized Fuzzy Decision Matrix (Cost Criteria).

\begin{tabular}{|c|c|c|c|c|c|}
\hline \multirow{2}{*}{ Criteria } & \multicolumn{5}{|l|}{ Alternative } \\
\hline & A1 & $\mathrm{A} 2$ & A3 & $\mathrm{A} 4$ & A5 \\
\hline C1 & $(0.333,1,3)$ & $(0.333,0.739,1.800)$ & $(0.333,0.680,1.800)$ & $(0.333,0.810,1.800)$ & $(0.429,1.308,9)$ \\
\hline C2 & $(0.556,0.920,1.800)$ & $(0.556,0.739,1.800)$ & $(0.556,1.533,9)$ & $(0.556,1.353,3)$ & $(0.556,1.095,1.800)$ \\
\hline $\begin{array}{l}\text { C3 } \\
\text { C4 } \\
\text { C5 }\end{array}$ & $\begin{array}{l}(0.111,0.882,9) \\
(0.556,0.913,1.800) \\
(0.429,1.154,7)\end{array}$ & $\begin{array}{l}(0.111,0.882,3) \\
(0.556,1.400,9) \\
(0.600,1.667,7)\end{array}$ & $\begin{array}{l}(0.143,1,3) \\
(0.556,1.105,3) \\
(0.429,1.154,7)\end{array}$ & $\begin{array}{l}(0.111,1.154,9) \\
(0.714,1.615,9) \\
(0.600,1.667,7)\end{array}$ & $\begin{array}{l}(0.111,0.714,1.800) \\
(0.556,1.105,3) \\
(0.600,1.667,7)\end{array}$ \\
\hline
\end{tabular}

In this study, the values of FPIS and FNIS have been fixed to $(1,1,1)$ and $(0,0,0)$ respectively. This value, as referred to Chen's method, is considered as the perfect value. The distance of each alternative is calculated by using equations (2), (10) and (11)

Table 10: Distances of Alternatives from FPIS.

\begin{tabular}{|c|c|c|c|c|c|}
\hline \multirow{2}{*}{ Criteria } & \multicolumn{5}{|c|}{ Alternative } \\
\hline & $\mathrm{A} 1$ & $\mathrm{~A} 2$ & A3 & A4 & A5 \\
\hline C1 & 4.851 & 5.135 & 5.243 & 5.035 & 3.625 \\
\hline C2 & 5.898 & 5.531 & 4.994 & 5.135 & 5.531 \\
\hline C3 & 4.810 & 4.798 & 3.633 & 4.718 & 4.917 \\
\hline C4 & 5.531 & 4.917 & 5.159 & 3.733 & 5.159 \\
\hline C5 & 2.719 & 1.754 & 2.719 & 1.754 & 1.754 \\
\hline Total $d_{x}^{*}$ & 23.809 & 22.136 & 21.749 & 20.375 & 20.988 \\
\hline
\end{tabular}


Table 11: Distances of Alternatives from FNIS.

\begin{tabular}{|c|c|c|c|c|c|}
\hline \multirow{2}{*}{ Criteria } & \multicolumn{5}{|c|}{ Alternative } \\
\hline & $\mathrm{A} 1$ & $\mathrm{~A} 2$ & $\mathrm{~A} 3$ & A4 & A5 \\
\hline C1 & 1.836 & 1.140 & 1.127 & 1.156 & 5.257 \\
\hline C2 & 1.210 & 1.258 & 5.281 & 1.927 & 1.258 \\
\hline C3 & 5.221 & 1.807 & 1.828 & 5.239 & 1.120 \\
\hline C4 & 1.209 & 5.268 & 1.874 & 5.295 & 1.874 \\
\hline C5 & 4.103 & 4.169 & 4.103 & 4.169 & 4.169 \\
\hline Total $d_{x}^{-}$ & 13.580 & 13.642 & 14.213 & 17.786 & 13.667 \\
\hline
\end{tabular}

Table 12: Computation of $d_{x}^{*}, d_{x}^{-}$and $C C_{x}$

\begin{tabular}{lllll}
\hline Rank & $d_{x}^{*}$ & $d_{x}^{-}$ & $C C_{x}$ & Alternative \\
\hline $\mathbf{1}$ & 20.375 & 17.786 & 0.4661 & A4 \\
$\mathbf{2}$ & 21.749 & 14.213 & 0.3952 & A3 \\
$\mathbf{3}$ & 20.988 & 13.677 & 0.3945 & A5 \\
$\mathbf{4}$ & 22.136 & 13.642 & 0.3813 & A2 \\
$\mathbf{5}$ & 23.809 & 13.580 & 0.3632 & A1 \\
\hline
\end{tabular}

The closeness coefficient $C C_{x}$ represents the distances to FPIS and FNIS simultaneously. Based on Table 12, the closeness coefficient $C C_{x}$ can be calculated using equation (12) which by dividing the value of distance for respective alternative from FNIS with the total value of distance for respective alternative from both FPIS and FNIS. For overall ranking, alternative A4 which is lack of education comes with the greatest value of closeness coefficient which is 0.4661 making it the most significant factor of committing crime followed by A3 which is peer pressure. Alcohol and drug abuse, family problems and poverty follow at the third, fourth and fifth ranked.

\section{CONCLUSION AND RECOMMENDATION}

Overall, throughout the evaluation of the factors using Fuzzy TOPSIS, lack of education is the most significant factor that causes one to commit crimes. The factor comes with the greatest closeness coefficient value which is 0.4661 . Meanwhile, the least contributing factor in committing crimes is poverty with the closeness coefficient value of 0.3632 . The results of this study clearly show how important it is for one to have a proper education background. Further work can be done by other researchers to improve and expand this study. Future researchers may use many other techniques such as Fuzzy Analytic Hierarchy Process (AHP) to rank the factors of committing crimes. A different result might be obtained if the technique mentioned above is being used. Next, many other precise factors of committing crimes can be used as the alternatives. Plus, to be more accurate, providing along the subcriteria might be useful to obtain a better understanding and better precaution steps. 


\section{REFERENCES}

Abdullah, L., \& Zamri, N. (2010). Ranking of the factors associated with road accidents using Correlation Analysis and Fuzzy TOPSIS. Australian Journal of Basic and Applied Sciences, 4(2), 314-320.

Anspal, S., Jarve, J., Kallaste, E., Kraut, L., Rais, M., \& Seppo, I., (2011). The cost of school failure in Estonia.

Azizi, A., Aikhuele, D. O., \& Souleman, F. S. (2015). A Fuzzy TOPSIS model to rank automotive suppliers. Procedia Manufacturing, 2, 159-164.

Brown, R., \& Velasquez, A. (2017). The effect of violent conflict on the human capital accumulation of young adults. Journal of Development Economics, 127, 1-12.

Erdebilli, B., \& Saputro, T. E. (2013). Supplier selection using integrated Fuzzy TOPSIS and MCGP: A case study. Procedia-Social and Behavioral Sciences, 116, 3957-3970.

Esiri, M. O. (2016). The influence of peer pressure on criminal behaviour. IOSR Journal of Humanities ND Social Sciences Ver III, 21(1), 8-14.

Ghani, Z. A. (2017). A comparative study of urban crime between Malaysia and Nigeria. Journal of Urban Management.

Kabir, G., \& Hasin, M. A. A. (2012). Comparative analysis of TOPSIS and Fuzzy TOPSIS for the evaluation of travel website service quality. International Journal for Quality Research, 6(3), 169185.

Khan, A. (2015). Throwing light on crime statistics. The Star. Retrieved April 15 April, 2017 from https://www.thestar.com.my/news/nation/2015/04/19/throwing-light-on-crime-statistics-it-is-not-just about-the-numbers-but-what-we-do-about-them-that-m/

Lochner, L. (2004). Education, work, and crime: A human capital approach. National Bureau of Economic Research.

Mor, D., \& Ramachandran, M. (2017). Optimization of solid wastes disposal strategy by Fuzzy TOPSIS method. Nature Environment and Pollution Technology, 16(1), 247-250.

Shahrudin, H.S. (2016). Malaysia's crime index sees 4.6 percent increase. New Straits Times. Retrieved April 24, 2017 from https://www.nst.com.my/news/2016/05/144196/malaysias-crime-index-sees-46cent-increase

Sidhu, A.S. (2005). The rise of crime in Malaysia: An academic and statistical analysis. Journal of the Kuala Lumpur Royal Malaysia Police College, (4), 1-28.

Sodhi, B., \& Prabhakar, T.V. (2012). A simplified description of Fuzzy TOPSIS. The Hindu (2016). Broken families, failed education push children into crime: Survey. The Hindu. Retrieved September 22, 2017 from http://www.thehindu.com/news/national/other-states/Broken-families-failed-educationpush-children-into-crime-survey/article14997503.ece 
The Malaysian Digest. (2014). Young and certainly getting dangerous: The rise of juvenile criminals. Malaysian Digest. Retrieved April 24, 2017 from http://www.malaysiandigest.com/features/523273young-and-certainly-getting-dangerous-the-rise-of-juvenile-criminals.html

The Times of India (2016). Poverty is the main cause of crime: Justice Markandey Katju. The Times of India. Retrieved September 21, 2017 from https://timesofindia.indiatimes.com/city/kochi/poverty-isthe-main-cause-of-crime-justice-markandey-katju/articleshow/56098486.cms 